ber of other activities for the near future. A series of handbooks, brochures and directories, ranging in coverage from carcers in oceanography. to publicity on important new research areas, to lists of oceanographers, both national and international. would be useful. We are negotiating now with potential funding sources, both national and international. We would hope to be able to provide some of the descriptive material in videotape and to have lists in computer-compatible as well as hard copy format in order to distribute these widely.

The Society can also be involved in educational issues. We hope to offer support to the periodic meetings of the "Oceanography Deans," perhaps by publishing and widely distributing the results of those meetings about graduate education of oceanographers.

Education about science in general and oceanography in particular extends also to the general public and decision-makers in state and federal levels. Better publicity for important new research thrusts ranging from individual research programs to proposed large cooperative programs is needed, especially in these days of constrained budgets. This is a message we hear continually in Washington from our friends in Congress. and I was not surprised to hear it again recently in the U.K. from a Member of Parliament who has a long-term interest in science.

Internationally, we all know that oceanographers are growing more dependent on each other. Pooling of resources and facilities to do global programs is becoming commonplace. The Society can help on this broad front by encouraging an international membership and a broader awareness of international programs.

We already have significant membership from outside the U.S., with members from Australia. Brazil, Canada, the Federal Republic of Germany, France, India, Israel. Japan, Korea. Monaco and the U.K. To increase non-U.S. participation, we have in the past two months begun an international mailing.

Because of the rapid increase in membership, we have hired professional help. Martha Cutkosky is now working part time in our Washington office to process membership applications and other related matters, and Therese Samodral is working part time at Texas A\&M University as an editorial assistant for David Brooks. We convey our special thanks to the volunteers who have cheerfully and efficiently undertaken all the initial tasks, from stuffing and mail- ing envelopes. to developing mailing lists, to processing applications. In the Washington office, these people are Carole Andersen. Emily Baker. Leonard Johnson. Sirpa Hakkinen, Jim Rucker and Richard Vetter. Thanks also go to Rebecca Grimes. Doris Rucker and Allison Burns of Joint Oceanographic Institutions. Inc.: they have provided vital assistance in these early days of the Society. At Texas A\&M, we are indebted to Letty Benning, who managed the myriad details of producing the magazine, and to Norman Martin. of the Sea Grant Program, for his exemplary services in artistic design. Without the gracious efforts of these volunteers, the Society and the magazine would not have flourished.

Our office is conveniently located in downtown Washington at 1755 Massachusetts Avenue. Northwest, where on the seventh floor we share three offices and a conference room with the American Meteorological Society and the University Corporation for Atmospheric Research. We are next door to the consortium for Deep Observation and Sampling of the Earth's Continental Crust, and one floor below Joint Oceanographic Institutions Incorporated. The office is just two blocks from the Dupont Circle Metro Stop (Red Line). If you 're in the neighborhood, please stop by and say hello.

\title{
Status of Sea-WIFS, TOPEX AND NSCAT: NEWS FROM NASA
}

\section{By W. Stanley Wilson}

FOLLOWING the meeting of the EOSAT Board of Directors on October 6. 1988, an agreement-in-principle is being refined by NASA and EOSAT concerning the flight of Sea-WiFS on the Landsat- 6 satellite in late 1991, subject of course to success with a pending funding initiative (see list below for definitions of acronyms). The mission specifications are not fully defined at this time, but it is anticipated that the essential requirements of the research community will be met with this mission.

Both TOPEX and NSCAT were cut by Congress during the Fiscal Year 89 budget process. The FY 89 Operating Plan, proposed by NASA in response to the congressionally appropriated budget, shows TOPEX reduced by $\$ 14.8 \mathrm{M}$, whichcoming after $\$ 16 \mathrm{M}$ and $\$ 15 \mathrm{M}$ reductions in FY 87 and FY 88-will result in a delay of some four to six months beyond the previously planned December 1991 launch date. The FY 89 reduction will not affect the level of support for the TOPEX AO investigator team.

With the second (and final) cancellation of NROSS in 1987, NSCAT was proposed for flight on the Japanese ADEOS mission. While NSCAT's prospects look excellent, formal selection will not occur until late October [after press time for this issue Ed.l. The proposed FY 89 Operating Plan

W. Stanley Wilson, NASA Headquarters, 600 Inde pendence Ale.. S.H. líashington, D.C. 20546. reinstates $\$ 4.8 \mathrm{M}$ of the $\$ 10 \mathrm{M}$ congressional cut, to allow development to continue in FY 89 and 90 at a pace that will enable NSCAT to meet the ADEOS schedule, which currently has a launch goal of early 1994. Congressional approval of the proposed Operating Plan is anticipated, but the outcome will not be certain until late in October.

The reduced level of funding has resulted in the reassignment within JPL of 21 members (one-third) of the NSCAT Project Team and a $75 \%$ cut in support for its $\mathrm{AO}$ investigator team.

\section{Acronyms and Abbreviations}

EOSAT: Earth Observation Satellite Company (the commercial operator of the Landsat series of satellites)

NASA: Natıonal Aeronautics and Space Administration

Sea-WiFS: Compact Wide Field Sensor (an Improved version of the Coastal Zone Color Scanner which flew on the Nimbus-7 satellite)

TOPEX: Ocean Topography Experiment (a dedicated altimeter mission)

NSCAT: NASA Scatterometer (a satellite sensor to measure the global wind field)

AO: Announcement of Opportunity (a means to formally solicit proposals; the successful proposers constitute the team of scientists to work with a given satellite mission)

NROSS: L.S. Navy Remote Ocean Observing System (a sitellite on which NSCAT was originally to have flown)

ADEOS: the Japanese Advanced Earth Observation Satellite

JPL: Jet Propulsion Laboratory (the institution which is responsible for both the TOPEX and NSCAT missions) 